\title{
Study on the Talent Training Mode of Higher Vocational Education and Social Economic Development in Ethnic Areas
}

\author{
Yihui Wang \\ Urban Vocational College of Sichuan, Sichuan Chengdu, China
}

\begin{abstract}
Higher vocational education has entered into in order to improve the personnel training quality, improve the ability of social service, and highlight the school characteristics for the in tension of the character development in the new period. Higher vocational colleges should strengthen for local economic and social development of radiation and contribution rate, you first need to in the talent training mode of reform and innovation, to enhance services to the nation's social and economic applicability, thus fulfilling the social service function raised to a new level.
\end{abstract}

Keywords: Talent training mode; Mate.

\section{The role of Higher Vocational Education on the social and economic development of Ethnic Areas}

The economic development in ethnic areas is mainly through several factors to prompt the change of Higher Vocational Education System like the adjustment and optimization of industrial structure, the choice of development model, the driving of ownership structure, and so on. Industrial structure is the key of local economic development. Different areas will form a different industrial structure layout according to their own resources superiority and the national macro strategic layout. And different industrial structure has different needs on higher vocational education disciplines (professional) system, personnel training level and specifications. In particular, it is worth pointing out that the industrial structures of the country are showing a cluster development trend. Industrial cluster has economic scale effect, which will form a chain of talent demand, such as the formation of the productive service industry talent chain around the manufacturing industry and the association talent chain around the upstream and downstream of the products. Industrial cluster will concentrate on a large demand of the talents with a profession, and form an exclusion of talents with other profession. So it demands that the higher vocational education discipline system is not large and full, but small and fine with rapid response capability.

The plight of Vocational Education in ethnic areas includes the lack of funds, the loss of talents and other issues of concern. And it also includes the negative effect of the recessive inversion and the loss of education resources [1]. The most prominent in these difficulties is the lack of talents which restricts the rapid development of economy. An important way to solve this problem is to develop higher vocational education. At the same time, only the economy has developed rapidly in ethnic areas, the development of higher vocational education in ethnic areas can have a good foundation. Therefore, it is necessary to form a positive interaction between the higher vocational education and the local economic development in ethnic areas so as to realize the sustainable and stable development of the two.

\section{The talent training mode under the matching of higher vocational education and social economy in ethnic areas}

The mode of talent cultivation is a kind of standard construction style and operation mode in the course of training to achieve the training objectives under the guidance of a certain educational theory and educational theory [2]. The talent training mode specifies the choice of teaching content, the integration of the direction, but also restricts the choice of teaching methods and teaching means.

Due to the different focus of industrial structure, the level of economic development and economic development, the economic development of ethnic areas in different periods demonstrate different characteristics. Similarly, it will propose a matching request on talents on the knowledge structure, 
professional ability and quality. Therefore, when higher vocational education serves for ethnic areas, it should make analysis from the angle of the social and economic development and its demand for the scale, types, levels and professional post group of the talents and combines the cultivation targets with the social economy development practice of ethnic areas. It not only make the talent cultivation plan accord with the general rules of higher education, but also take into account the special rules of social economy development in the ethnic area, so as to construct a talents training mode suitable for the economic and social development in ethnic areas.

\subsection{Order Form' Talents Training Pattern}

'Order form' talents training mode is the most commonly used pattern for current vocational education in the deep cooperation between college and enterprise, namely a school signs labor contracts according to the needs of the employer and makes cooperation in technology, equipment, teachers, etc. by using both resources of cooperation. And it's a cooperative school running mode to co-cultivate personnel [3]. This mode has been widely adopted by employers and vocational colleges, and forms a certain paradigm.

After many years of practice, there are three types of the relatively mature order training mode (see Figure 1):

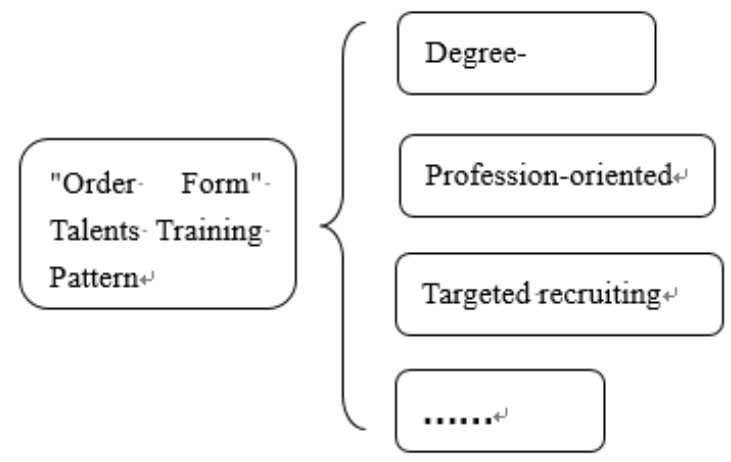

Figure 1 'Order-form' training mode of school enterprise cooperation

Degree-oriented mode. Degree-oriented education refers to the enrollment, teaching and targeted training in the students' education stage according to the employers' needs. The general operation method of Degree-oriented mode is as follows. First, enterprise and the school sign a talent training cooperation order agreement. Secondly, enterprise and the school agree on the talents training objectives and specifications. Then, the cooperation between school and enterprise implement the enrollment, teaching and practice plan. Finally, employers choose and employ graduates according to cooperation agreement.

Profession-oriented mode. After the vocational colleges complete the teaching task of public basic courses and professional courses, and it will reach a cooperation agreement with employer, and make the class transfer into the enterprise to complete professional courses teaching and internship. After the graduation of students, they will be hired by employer. The general operation method of Profession-oriented mode is as follows. First, enterprise and school sign a talent training cooperation agreement. Secondly, enterprise and the school agree on the talents training objectives and specifications. Then, the combination of school and enterprise implement professional teaching and internship program. Finally, the employer selects and hires graduates according to cooperation agreement.

Targeted recruiting mode. Employer and vocational colleges cooperate to recruit students, and carry on a certain period of professional ethics and job skills training according to the requirements of professional positions. After the students have obtained the corresponding vocational qualification certificate, the employer according to the cooperation agreement to select and employ. The general operation method of Targeted recruiting mode is as follows. First, enterprise and the school sign a talent training cooperation order agreement. Secondly, enterprise, both sides agree talents training objectives and specifications. Then the cooperation between school and enterprise implement the 
students recruiting, teaching and practice plan. Finally, employer chooses and hires students according to cooperation agreement.

The whole process of this kind of talent training pattern itself from the target position determination to the training scheme design, teaching plan making, teaching organization implementation and teaching quality evaluation is completed in the school enterprise cooperation and employer directly reserves needed talents from the graduates. Its advantages mainly lie in three points: first, the cultivation according to the talent needs of the enterprise has strong pertinence; second, students, through the co-cultivation of schools and enterprise, greatly reduce the frequency of personnel flow and the loss of talents flow; third, it saves the inputted personnel, material, capital and financial time for hiring, keeping and cultivating people. For the ethnic areas, the former recruited personnel are difficult to long-term work in ethnic regions because of different living habits, personal conditions and cultural background, so the loss of personnel is serious, causing loss of economic and cultural development in ethnic areas. But this 'order form' recruiting has strong pertinence and purpose, which can really train a large number of talents with a certain academic level, certain technical ability and it's a major breakthrough to strengthen the construction of talent team in ethnic regions.

\subsection{Learn in work and work in learn' talent training mode}

'Learn in work and work in learn' talent training mode is a kind of work-study combination cultivation mode. Namely, starting from the technical personnel needs of local enterprise in ethnic area, through the connotation construction of 'building production enterprises on campus and building practical training base in the outside enterprises', it forms a work-study combination cultivation mode of containing each other.

'Learn in work and work in learn' talent training mode can be realized in two ways. One is the construction of production enterprises in the school. Namely college provides space and the part of equipment, enterprises provide all or part of the equipment, in accordance with the requirements of the enterprise to establish a real working environment and take the enterprise actual product production to train students and let students work on the line. This mode allows students do not need to leave the school, but also they can get training in enterprise. So it combines the school's educational advantages with enterprise business advantages to complete the training of talents. The second is establishment of a training base off campus in enterprises. Namely, the training base is built in extracurricular enterprise. The working and learning alternation, internship are embedded in the enterprise to realize the seamless connection of the students employment and business needs. This mode organically combines the students' skills, professional quality, professional ethics culture with factory production, technological innovation, forming a work-study combination cultivation mode of complementary advantages and mutual benefit and reaching a win-win situation of running benefit and economic benefits.

'Learn in work and work in learn' talent training mode can realize the organic combination of school training and internships in enterprises, realize the gradual roles change from "students, apprentices, workers to high skilled talents to make the seamless connection between graduation and employment. For ethnic areas, this talent training mode helps local businesses to find and cultivate reserve personnel, reduce personnel mobility. And students are able to feel the real work environment so as to understand the requirements on their own, which is conducive to choose the rational employment and employment positions and establish a correct concept of occupation.

\subsection{Courses and certificates integration" talent training mode}

Literally speaking, "course" refers to professional courses, "certificates" are on behalf of professional certificates. "Courses and certificates integration ", is also known as double certificates teaching, which refers to that the curriculum corresponds to the professional certificates and the course materials and teaching content are consistent with and certificate content. Through the course of study, students will be able to directly participate in the professional certificate examination to achieve the "double certificate". 
The teaching process of some professions like accounting, logistics, software in higher vocational colleges can organically combine the National Occupational Skill Testing and assessment requirements with professional daily teaching content. The curriculum specified on this basis can make students complete the courses, at the same time obtain the professional qualification certificate, forming 'course and certificate integration' talent training mode.

The national civil committee and educational department point out on 'opinions on accelerating vocational education reform and development of ethnic minorities areas': 'vocational education during senior high school stage should continue to improve the system academic certificates, training certificates and professional qualification certificates simultaneously and gradually implement labor preparation system and employment system and make urban labor first get training then employment.' At present, there are a few people with the qualification certificates such as software, marketing, psychological consulting, accounting and so on which are urgently-needed in ethnic areas. The implementation of "course and certificate integration" in higher vocational colleges is the key to implement the "double certificate system", which can not only improve the students' professional quality, but also enhance their employment competitiveness.

To perfect and innovate the talent training mode that matches the social and economic development in the ethnic areas should always adhere to the purpose of serving the economic construction and social development of ethnic regions. From the national regional productivity development level, economic structure, industrial structure demand and ethnic areas' actual situation, it should earnestly learn from the advanced experience of other countries and the domestic developed area, with full respect for the rules and characteristics of vocational education, to continuously explore talent cultivation mode in line with national regional characteristics. Of course, higher vocational education talent culture mode is not the only and fixed one, but should flexibly change and combine according to the talent requirements proposed by ethnic areas' social and economic development and the degree of connection between higher vocational colleges and ethnic areas.

\section{Summary}

Higher vocational education has irreplaceable function in promoting social and economic growth in national regions; which are the core element and driving force to promote economic growth and enhance regional comprehensive competitiveness in national regions. All that is the personnel training mode of higher vocational education which play a critical role, it is the basic condition of survival and development of higher vocational colleges. Therefore, personnel training mode higher vocational education should be guided by the social economy demands of in national regions, break the mode and structure of single personnel training, strive to strengthen connotation of higher vocational education, service ability of social economy in national regions are improved through participation in production, project consultation, technology development, vocational training, skills identification methods and so on.

\section{References}

[1] Lan Jie. The plight and prospect of higher vocational education in ethnic areas [J]. Vocational education and communication, 2016, 13:56-59.

[2] Cai Xiaorong, Kong Yuanfa. The construction of talent training mode in higher vocational college [J]. Journal of Chongqing Electric Power College, 2010, (1).

[3] Huang Muhua. Current situation analysis of 'Order form' talent training mode in higher education [J]. Education (Higher Education Forum), 2016, 21:16-17. 